\title{
Coherent optical systems implemented for business traffic routing and access: the RACE COBRA project (invited)
}

Citation for published version (APA):

Bachus, E. J., Almeida, T., Demeester, P., Depovere, G. F. G., Ebberg, A., Rui Ferreira, M., Khoe, G. D., Koning, O., Marsden, R., Rawsthorne, J., \& Wauters, N. (1996). Coherent optical systems implemented for business traffic routing and access: the RACE COBRA project (invited). Journal of Lightwave Technology, 14(6), 1309-1319. https://doi.org/10.1109/50.511663

DOI:

$10.1109 / 50.511663$

Document status and date:

Published: 01/01/1996

\section{Document Version:}

Publisher's PDF, also known as Version of Record (includes final page, issue and volume numbers)

\section{Please check the document version of this publication:}

- A submitted manuscript is the version of the article upon submission and before peer-review. There can be important differences between the submitted version and the official published version of record. People interested in the research are advised to contact the author for the final version of the publication, or visit the $\mathrm{DOI}$ to the publisher's website.

- The final author version and the galley proof are versions of the publication after peer review.

- The final published version features the final layout of the paper including the volume, issue and page numbers.

Link to publication

\section{General rights}

Copyright and moral rights for the publications made accessible in the public portal are retained by the authors and/or other copyright owners and it is a condition of accessing publications that users recognise and abide by the legal requirements associated with these rights.

- Users may download and print one copy of any publication from the public portal for the purpose of private study or research.

- You may not further distribute the material or use it for any profit-making activity or commercial gain

- You may freely distribute the URL identifying the publication in the public portal.

If the publication is distributed under the terms of Article 25fa of the Dutch Copyright Act, indicated by the "Taverne" license above, please follow below link for the End User Agreement:

www.tue.nl/taverne

Take down policy

If you believe that this document breaches copyright please contact us at:

openaccess@tue.nl

providing details and we will investigate your claim. 


\title{
Coherent Optical Systems Implemented for Business Traffic Routing and Access: The RACE COBRA Project
}

\author{
Ernst-Jürgen Bachus, Teresa Almeida, Piet Demeester, Member, IEEE, Geert Depovere, \\ Alfred Ebberg, Mario Rui Ferreira, Giok-Djan Khoe, Fellow, IEEE, Oscar Koning, \\ Richard Marsden, John Rawsthorne, and Nico Wauters
}

(Invited Paper)

\begin{abstract}
The RACE COBRA consortium has performed four field trials to verify the suitability of dense WDM combined with heterodyne detection (for which the term CMC, "Coherent Multicarrier" is used) for different network applications. The main advantage in using heterodyne detection is the simple access to individual optical channels by only switching local lasers to the desired channel. Heterodyne detection acts as a perfect optical filter. Thus, a plurality of dense spaced optical carriers can be placed, e.g., within one WDM window. The additional freedom in the channel multiplex provides some advantages which are shown in the demonstrators: A routing flexibility in the RENO (Reconfigurable Node) cross-connect demonstrator supporting STM-16 at Philips Research in Eindhoven. A routing flexibility in the demonstrator at BBC in Kingswood Warren, UK, supporting uncompressed HDTV communication in a studio environment. By shifting switching functions to the terminals, the network is kept completely passive. This is also obtained in the local area videoconference trial at CET in Aveiro, Portugal, using high quality standard TV and in the BCPN trial at KPN Research in Leidschendam, NL, where ATM-streams are supported for multimedia services. The paper outlines the demonstrator concepts as well as some subsystems and key components developed by the consortium.
\end{abstract}

\section{INTRODUCTION}

$\mathbf{O}$ NE OF the objectives of the RACE program was to promote the competitiveness of the community's telecommunications industry, operators, and service providers in order

Manuscript received April 28, 1995.

E.-J. Bachus is with the Heinrich-Hertz-Institut, Einsteinufer 37, 10587 Berlin, Germany.

T. Almeida and M. R. Ferreira are with the Centre de Estudos de Telecomunicacoes, Rua Eng. Jose Ferreira Pinto Basto, 3800 Aveiro, Portugal.

P. Demeester and N. Wauters are with the Department of Information Technology, University of Gent-IMEC, Gent, Belgium.

G. Depovere is with Philips Research Laboratories, 5656 AA Eindhoven, The Netherlands.

A. Ebberg was with Siemens AG, Corporate Research and Development, 81730 Minchen, Germany. He is now with the Fachhochschule Westkueste 25746 Heide, Germany.

G.-D. Khoe is with the University of Technology Eindhoven, $5600 \mathrm{MB}$ Eindhoven, The Netherlands.

O. Koning is with Royal PTT Nederland N.V., KPN Research, 2260 AK Leidschendam, The Netherlands.

R. Marsden is with British Broadcasting Corporation, Research and Development Department, Kingswood Warren, Tadworth, Surrey, KT20 6NP, U.K.

J. Rawsthorne is with GEC-Marconi Materials Technology Limited, Caswell, Towcester, Northants, NN12 8EQ, U.K.

Publisher Item Identifier S 0733-8724(96)04779-2. to make available to final users the services which will sustain the competitiveness of the European economy. The COBRA consortium reflects this objective by including among its partners two network operators and one service provider, as well as three industrial partners and two research institutions. The consortium was therefore in a position to investigate from many aspects the potential of innovative systems for short and medium term IBC (Integrated Broadband Communication) implementation.

Since IBC was first defined as the objective for the RACE program, there has been an important shift in perception. The orientation of the work has shifted from "Exploring Options" under RACE Phase I to "Preparing for Implementation" under Phase II. Work carried out in the COBRA project is aimed toward this latter exercise. Emphasis is placed on the exploitation of the optical frequency domain by coherent techniques, but other technologies are used as well where appropriate. Examples are the use of ATM in the KPN Research field trial, the coexistence of the WTDM system in the TV studio BCPN, and the use of SDH interfaces and optical space switches in the optical RENO cross-connect demonstration.

\section{COBRA CONSORTIUM AND RACE CONTRIBUTIONS}

The RACE Phase II project R2065 COBRA (Coherent Optical systems implemented for Business traffic Routing and Access) covered the period of 1992-1995. The project participants are Philips (prime contractor), the Heinrich-HertzInstitut (HHI), GEC-Marconi Materials Technology Limited, Siemens AG, Interuniversity Microelectronics Centre (IMEC), British Broadcasting Corporation (BBC), Centro de Estudos de Telecomunicacoes (CET), and PTT Telecom, NL (and KPN Research as a subcontractor). Since 1994, the Project Leadership has been subcontracted by Philips to the Eindhoven University of Technology.

COBRA was a follow-up of the RACE Phase I project CMC (Subscriber Coherent Multichannel System). In the CMC project, an important highlight was the design and construction of an engineered CMC distribution system. In the COBRA project, the knowledge and techniques developed in the CMC project were further enhanced and four different but 
complementary multiwavelength systems were implemented in field trials.

The activities in COBRA have been split into different working groups: the WG Implementation coordinated the implementation of the demonstrators, the WG Technology specified the components and the link to the overall RACE program was established through the WG Systems. A public deliverable, the "COBRA-Report on Flexible Broadband Networks" was issued annually by this working group [1][4]. In these reports, the progress of the COBRA project was outlined and updated each year. Each COBRA Report also contains a summary of worldwide progress and trends in the area of multiwavelength networks and dedicated components.

The Working Group Systems also participated in a number of RACE activities such as the Project Line 1 (PL1) meetings and associated workshops, and Sub Technical Groups (STG's), which have been set up to draft specifications, and to provide essential inputs which are now included in the RACE Common Functional Specifications (CFS's) and in standardization proposals submitted to ETSI (European Telecommunications Standard Institute).

Cooperation with other RACE projects has been set up. The COBRA demonstrator at BBC shared the physical network simultaneously with the demonstrator of the RACE project WTDM. The network of the COBRA CET demonstrator permits the operating status of the demonstrator to be assessed by collecting information on the status of each network element. This specific activity has been performed in close cooperation with RACE project ICM. Also a Techno-economical analysis was carried out with assistance of RACE projects TITAN and INTERACT.

\section{OPTICAL NETWORK TRENDS AND COBRA}

The aim of this chapter is to point out main features of the COBRA concept for the optical networks in the demonstrators.

\section{A. Trends Toward High Capacity}

$10 \mathrm{~Gb} / \mathrm{s}$ transmission systems are already commercially available. The next generation of WDM systems focusing on four or eight wavelength channels within the EDFA band are under development. Impressive advances on the laboratory level have recently been shown: the transmission of $400 \mathrm{~Gb} / \mathrm{s}$ using optical TDM-processing techniques [5] and the arrival at the $1 \mathrm{~Tb} / \mathrm{s}$ bound through multiplexing of wavelength channels $(55 \times 20 \mathrm{~Gb} / \mathrm{s}$ [6] and $10 \times 100 \mathrm{~Gb} / \mathrm{s}$ [7]). The question arises, where the limit will be. In [8] the ultimate Shannon limit for the full band between $1.3 \mu \mathrm{m}$ and $1.6 \mu \mathrm{m}$ is estimated at $300 \mathrm{~Tb} / \mathrm{s}$. Pushing toward this frontier is of course an attractive approach. A distinct approach is to take an advanced but already engineered technique and to demonstrate various network applications. This was done in the COBRA project and is outlined in the following chapters.

\section{B. The COBRA Concept}

COBRA used a multiwavelength technology known as CMC (Coherent Multicarrier) developed in the RACE phase I project R1010 [9] which is based on optical heterodyne detection.
In a heterodyne receiver, the incoming signal is converted into a microwave signal by combining it with the light of a local oscillator laser at a slightly different frequency. The resulting intermediate frequency (IF) signal in the microwave region can be processed by conventional techniques which are well known from radio systems. The local laser frequency is locked to the signal light frequency by an automatic frequency control loop. Up to now this is the usual control scheme and also applied within COBRA.

The first obvious advantage offered by heterodyne detection is the high sensitivity of the receiver (and a corresponding long transmission span). With a sufficient amount of local oscillator power, a heterodyne receiver offers a sensitivity close to the shot-noise-limit. Meanwhile, this advantage has partly been eroded since the introduction of optical fiber amplifiers. The sensitivity of an optical direct detection receiver equipped with an optical fiber preamplifier approaches the sensitivity achieved with a heterodyne receiver.

1) Heterodyne Detection: A Perfect Optical Filter: The major advantages, however, offered by a heterodyne receiver are the selectivity and the tunability. A heterodyne receiver acts as a nearly perfect optical filter with very attractive features. The optical filtering function of the heterodyne receiver is determined by its electrical filter in the IF branch. In contrast to optical filters used in direct detection systems, multipole electrical filters of excellent passband characteristics are easily implemented in a coherent receiver. These nearly ideal optical filtering characteristics will be extremely useful when selecting a single optical channel from a high number of densly spaced channels transmitted on a fiber. A narrow channel spacing is advantageous, especially in the case of systems using a number of concatenated optical fiber amplifiers. As the frequency response of an optical fiber amplifier is not ideally flat, every additional amplifier reduces the available bandwidth leaving only a few nanometers in some cases.

Finally, the heterodyne receiver can be switched electrically to any desired frequency channel by changing the frequency of the local oscillator. Tuning can be performed very quickly compared to thermally or mechanically adjusted optical filters. A tuning range of more than $10 \mathrm{~nm}(>1 \mathrm{THz})$ [10] and a passband of around $1 \mathrm{GHz}$ can be realized simultaneously. In contrast to preamplified direct detection systems, heterodyne systems can be operated over the entire wavelength range of the optical fiber (e.g., from $1300 \mathrm{~nm}$ to $1600 \mathrm{~nm}$ ) and are not restricted to the passband of a particular optical amplifier. Note that the tuning range of semiconductor lasers is very large in principle. A continuous tuning of $242 \mathrm{~nm}$ ranging from 1.32 $\mu \mathrm{m}$ to $1.562 \mu \mathrm{m}$ has already been shown in [11]. Some recent advances in CMC technology are reported in [12]-[20].

In our terminology, the term CMC (Coherent Multicarrier) is used for (dense spaced) optical carriers (which all have to fulfill certain coherence-conditions) combined with heterodyne detection. Channel selection (which is a switching function) is performed within the receiver. Thus, in any cases, the optical path is terminated by the corresponding transmitter-receiver pair. (If one wishes to route transparent optical WDM channels through a network, frequency selective all-optical devices like multiplexer, filter, router, and frequency converter are 


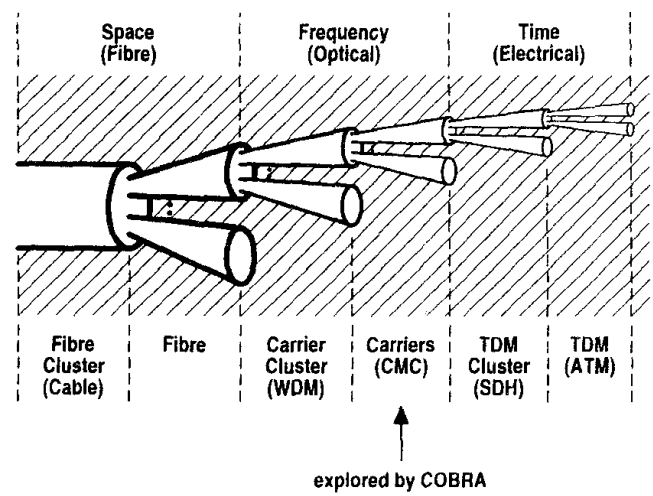

Fig. 1. Hierarchical structure of multiplexing. The COBRA project aims at the potential of the carrier "pipes" and the interaction with the others.

indispensible). Most of the key technical problems associated with heterodyne detection have already been addressed and solved during recent years [21], [9], [22], [23], [24]. The technical advantages of coherent systems are evident; however, it still remains to be shown that these systems are economically competitive compared to other solutions. A step toward cost reduction is the monolithic integration of a heterodyne receiver front end on a single chip [25], which has also been one activity within the COBRA project.

2) Illustration of the Multiplexing Concept: A layered transport network architecture for SDH has been commonly accepted and will be standardized by ITU [26]. The ITU-T recommendation G.803 also explicitely states, that "the necessity of an explicit description of a WDM layer in the transmission media layer is for further study." The concept can be extended with new layers representing optical multiplexing and cross-connect functionality as proposed in [27], [28], a WDM layer and a CMC layer. The additional CMC multiplexing explored by the COBRA consortium is illustrated in Fig. 1.

The style of this figure differs from that commonly used (showing the layered areas) in order to illustrate the fact that a WDM-channel is a bundle of CMC-channels, each CMCchannels a bundle of TDM-channels which itself may split into the layers of SDH and ATM.

Physical and logical topology of a network need not to be identical, and can be optimized independently. Logical reconfiguration of a network (for example, in the case of varying traffic or service demands), is possible without changing the physical topology. Furthermore, optical multicarrier technology can also attribute to network survivability, by offering a very flexible way of rerouting traffic. For these purposes the RENO's (see Ch. IV-A) act as optical carrier cross-connects providing a means for flexible optical network reconfiguration.

3) Main Features of the COBRA Concept: The main features of the COBRA concept shown in the demonstrators are summarized in brief:

-A fine granularity of wavelength channels. The channel spacing can be performed close to the bandwidth of the channels.

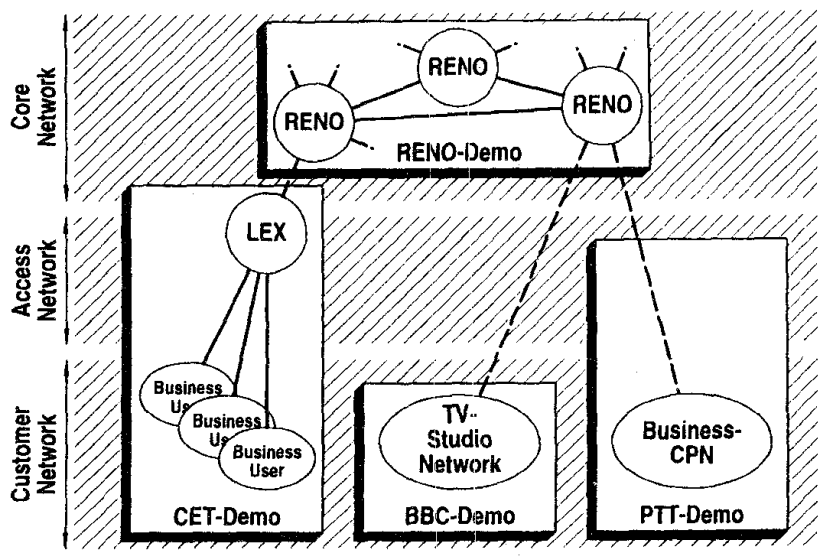

Fig. 2. The four COBRA demonstrators and the network segments covered by these demonstrators. ${ }^{\prime}$

-A dedicated wavelength channel for each application. This is shown for the transport modules of SDH (STM-1, STM-16), for uncompressed TV and HDTV distribution and for ATM-streams.

-COBRA networks are based on the broadcast-and-select principle. "Broadcast" by means of star-couplers, "select" by tuning of receivers.

-Optical paths are always terminated by the corresponding transmitter-receiver pairs. Each receiver performs a fully electrical regeneration of the digital signals (3R).

-No optical filters or multiplexers are used for discriminating individual CMC channels.

-Simple upgrading is possible by adding just more carriers (within the range of tunability and power budget).

- Unlimited cascadability is possible through modular subnetworks. The resulting multihop network is of course not all-optical.

-The optical COBRA networks are circuit switched networks (packet switching with $\mathrm{CMC}$ is indeed an important option for further investigations).

-Emphasis is laid on demonstrating practical applications including the management of the demonstrator networks.

\section{THE COBRA TRIALS}

The demonstrators have been chosen to illustrate different aspects of an overall communications network. The RENO demonstrator is a part of the core network, forming the switching centres at which SDH traffic is routed [29]. The three other demonstrators address three types of BCPN, each with specific customer requirements (Fig. 2).

The individual demonstrators are now outlined by short descriptions and figures followed by a table summarizing their main parameters.

\section{A. The RENO Core Network}

The general structure of a single RENO (Reconfigurable Node) is shown in Fig. 3. The maximum number of fibers and carriers per fiber is assumed to be $N$ and $M$, respectively. The

${ }^{1}$ The drawn lines in the figure are indicating optical connections, not necessarily single fibers. A connection may consist of a single fiber (duplex mode) or two fibers (simplex mode). 


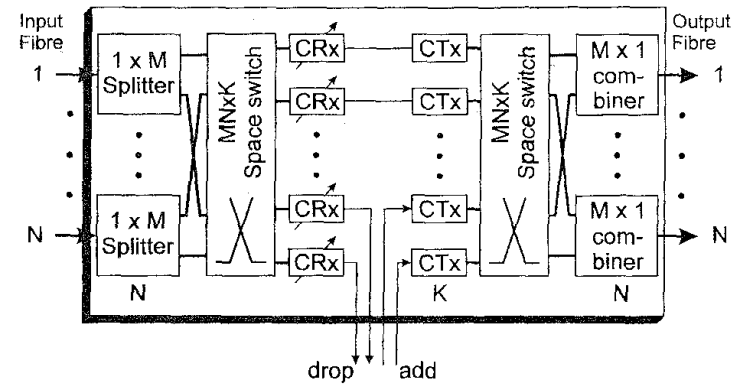

Fig. 3. General structure of the RENO's (Reconfigurable Nodes). CT $x$ is a Coherent Transmitter at a fixed optical frequency, $\mathrm{CR}_{x}$ is a Coherent Receiver switchable to any of the $M$ carriers $(K \leq M N)$.

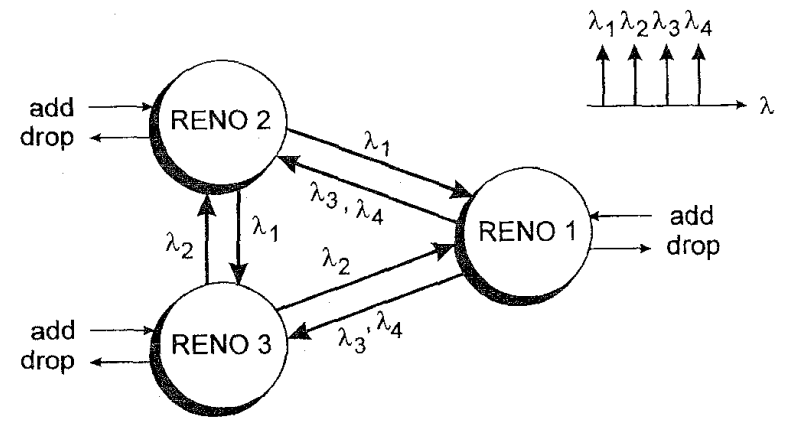

Fig. 4. The RENO core network demonstrator.

incoming carriers are transferred through the RENO to the outgoing fibers via space switch matrices and $\mathrm{CR}_{x}-\mathrm{CT}_{x}$ pairs ("C" stands for coherent) performing the wavelength translation. Also add-drop-functions are implemented. The transmitters have a fixed wavelength, the receivers are tunable (it has to be mentioned here that a plurality of different node-architectures are possible to obtain the same functionalities). A part of a core network based on RENO cross-connects is depicted in Fig. 4. The nodes are interconnected by unidirectional optical fiber links. Generally, such nodes will be located in major cities, also interfacing via dedicated optical links to the local exchanges (LEX's). In the demonstrator all $\mathrm{CT}_{x}$ and $\mathrm{CR}_{x}$ are working at $2.5 \mathrm{~Gb} / \mathrm{s}$ for transmit and receive STM-16 signals of the $\mathrm{SDH}[30],[27]$. In [31] it is shown that the SDH management facilities can be used to locate errors (monitoring) and to transport network information across the optical layer (signaling). In [28] it is shown how signaling and surveillance facilities can be achieved through the addition of a low bitrate signal to each wavelength channels.

The RENO demonstrator is restricted in terms of available hardware ( 4 wavelengths for 3 RENO's), but illustrates the full capability of the RENO concept.

A typical feature of the RENO network is the possibility to adapt the traffic per fiber to changes in the actual short-term traffic demand [32]-[35]. Each transmitter can be allocated to any trunk. This is cost effective, because reductions in hardware requirements can be made through statistical traffic analysis, the number of $\mathrm{CR}_{x}-\mathrm{CT}_{x}$ pairs being determined using standard network planning techniques. Spare $\mathrm{CR}_{x}-\mathrm{CT}_{x}$ pairs may also be present to allow extra capacity for special events. These may also be used for replacing any $\mathrm{CR}_{x}-\mathrm{CT}_{x}$ pair that has become unavailable. In the case of a connection failure between two nodes, the total traffic between the two nodes may be easily rerouted via one or more other nodes of the network. This avoids the necessity for extra optical switch hardware and links.

Some nodes will in practice only interface with a small number of other nodes, and will consequently only have a limited number of $\mathrm{CR}_{x}-\mathrm{CT}_{x}$ pairs. Upgrading may be achieved by simply adding extra hardware modules (optical switch, tunable receiver, and transmitter), assuming that large enough optical splitters and couplers were initially installed. Performance studies which calculate the wavelength requirement and the survivability for realistic networks are published in [33], [34].

\section{B. Broadband Video Multi Access-The BBC TV Studio Network Demonstrator}

The objective of the BBC Demonstrator was to show an application of CMC technology in broadband routing-the transport of full-band television signals in a studio center. A coherent transmission layer has been specified and developed to determine the potential capacity of a practical network, and to show that coherent techniques are an effective means of extending close-spaced WDM. It is estimated that coherent techniques could increase the capacity of a conventional WDM system by about a factor of eight.

There is a requirement in a TV studio center to interconnect technical equipment on, say, an hour-by-hour or day-by-day basis, to draw together the technical facilities for a particular program production. (This is distinct from the rapid synchronized switching reqired for editing and program "cuts"). The network must be nonblocking, point-to-multipoint, with the capacity for several hundred video, audio, and ancillary signals.

RACE Projects R2001 and 1036 have developed a network to meet these requirements based on a combination of closespaced wavelength multiplexing and electrical multiplexing. This system, known as WTDM, provides only just enough capacity for a typical studio center. The work in COBRA shows the extra capacity and optical power margin offered by coherent techniques. This can be used for more signals, for HDTV as opposed to conventional TV signals, to increase network flexibility, or a combination of these. It has also been demonstrated that WTDM and CMC can operate on the same optical network. The ability to tune the $\mathrm{CMC}$ receivers eliminates some of the high-speed electrical switching that would be needed in a WTDM network.

The typical demonstration is shown in Fig. 5. The coherent layer itself consists of three sets of $2.5 \mathrm{~Gb} / \mathrm{s}$ transmission hardware (one each from GMMT, Philips and Siemens), and a central controller (developed by HHI and GMMT, and known within the project as the wavelength manager). The nominal channel spacing of the coherent transmitters is $0.25 \mathrm{~nm}$ (about $31 \mathrm{GHz}$ ), adjustable for experiments, grouped around 1553 $\mathrm{nm}$. The WTDM lasers operate at $2 \mathrm{~nm}$ intervals from 1530 


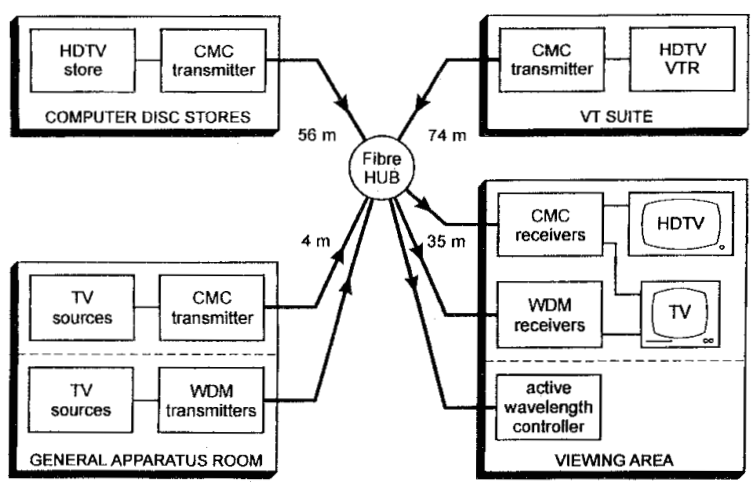

Fig. 5. The BBC Studio demonstrator: A merge of the RACE WTDM and the COBRA project. HDTV studio terminals in the COBRA partare communicating at the STM- 16 line bitrate of $2.5 \mathrm{~Gb} / \mathrm{s}$ (uncompressed digitized video channels in the payload). All the COBRA CMC channels fit into a single WDM slot of the WTDM testbed.

$\mathrm{nm}$ to $1560 \mathrm{~nm}$. The coherent transmitters and receivers are connected to the WTDM network's central optical star by additional $4 \times 4$ couplers, and in this arrangement replace the 1552 and $1554 \mathrm{~nm}$ channels. Program signals are connected to the network via SDH multiplexing equipment developed in R1036, and audio, TV, and HDTV interfaces developed in $\mathrm{R} 1081$. The bit rates of these signals range from $3.072 \mathrm{Mb} / \mathrm{s}$ to $1.152 \mathrm{~Gb} / \mathrm{s}$.

The system was originally demonstrated during September 1994. This demonstration linked a series of technical areas at the BBC's Research and Development Department in Surrey, UK, and was held as part of the Department's biannual "open days." COBRA equipment was used to convey signals ranging from audio to uncompressed HDTV over an existing optical network. The equipment was reassembled in March 1995 at RAI (Italien, State Television) Technical Research Center Turin, and a further trial was conducted in autumn 1995 at the main studios of NRK (the Norwegian State Broadcaster), Oslo. These last two events were collaborations with RACE 2001, WTDM Pilot.

\section{Videoconferencing in Aveiro Town--The CET Demonstrator}

The COBRA demonstrator implemented by CET in Aveiro aims at assessing the viability of videoconference services by means of coherent techniques for the transmission of digitized standard video signals over a PON with a star topology. Coherent equipment is used which was developed under the R 1010 project and designed for the distribution of high quality video channels at $140 \mathrm{Mb} / \mathrm{s} \mathrm{[36],} \mathrm{[37].}$

The field trial is based upon a standard singlemode fiber passive optical network (PON) transmitting video signals between three sites (CET, Telecom Shop and Telecoms Institute) Fig. 6. The PON is configured as a star scheme with one duplex fiber cable per user. For the purposes of system control, one output of the central four-by-four star coupler is monitored by an optical spectrum analyzer, allowing measurement of optical power and frequency stability.

The optical network is supported by an N-ISDN network running in copper symmetrical pairs. This network uses the

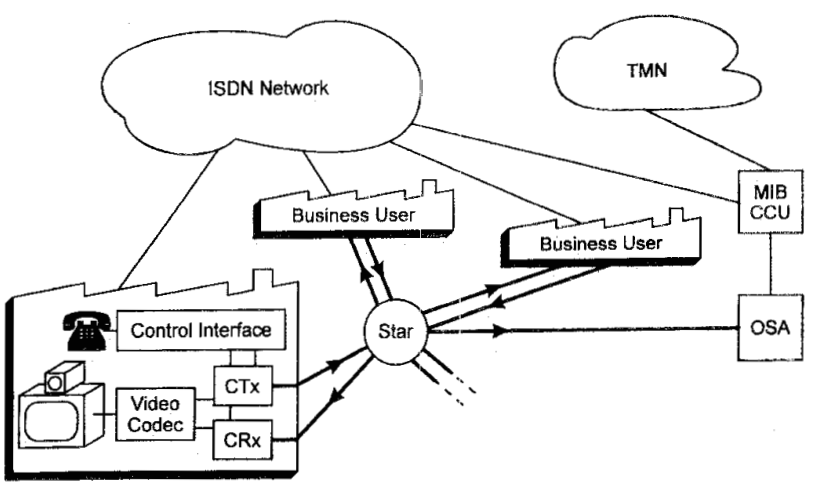

Fig. 6. The CET demonstrator designed for $140 \mathrm{Mb} / \mathrm{s}$ point-to-point videoconferences. The network is controlled via the ISDN Network by the Central Control Unit (CCU). Remote management of the demonstrator is performed by the TMN platform which has access to a Managed Information Base (MIB).

ELDIS Local Digital Exchange developed by CET and interconnects the Control Unit with each of the users premises. There, an ISDN phone set is connected to a PC featuring an ISDN card and through which both digitized voice/sound and control signals are to be passed. The network permits the remote management of the demonstrator by a PON TMN platform which has access to a Managed Information Base (MIB) located in the COBRA Control Unit (CCU). The CCU contains updated information on the status of each network element. The functionalities of this platform include alarm management and configuration monitoring. This activity has been performed in close cooperation with R2059 ICM.

The CET demonstrator was installed in the Aveiro town area using the existing duct and cable network infrastructure from Telecom Portugal. The distance between each of the users and the control center (CET) is not greater than $3 \mathrm{~km}$. Bidirectional interactive videoconference services (both point to point and point to multipoint) are available to business users, allowing telelearning/training and joint business meetings to be held. These define the requirements for the remote control of terminals.

In a realistic environment with a large number of users, a number of questions arise, answers to which are difficult to find from a small size demonstrator. These include spectrum management aspects, arbitration of the videoconferencing session, PON monitoring and alarm processing issues as well as delays introduced by network control. In addition, if less optical carriers are available than the total number of users, congestion is likely to occur and must be accommodated. These issues are studied using a network model with at least 100 users and a smaller number of available optical carriers. The results obtained complement the tests of the demonstrator.

\section{Multimedia Communication in Leidschendam-The PTT-BCPN Demonstrator at KPN Research}

It is generally expected that a future business customer premises network (BCPN) must deal with a large variety of broadband services, each specified by a different bit rate and traffic characteristic. In future BCPN's several connection types (like point-point, multipoint-multipoint, and point- 


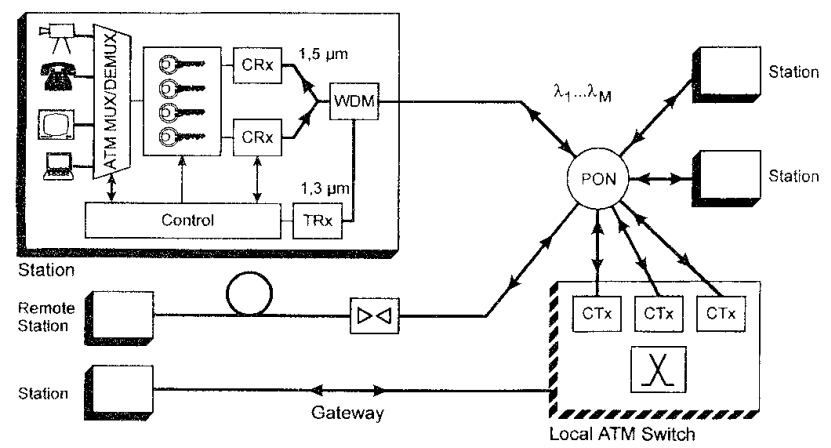

Fig. 7. The concept of the PTT-BCPN demonstrator at KPN Researchin Leidschendam, showing coarse WDM, CMC and ATM multiplexing TR $_{x}=$ transmitter and receiver working at $\lambda=1.3 \mu \mathrm{m}, \mathrm{CTR}_{x}=$ coherent transmitter and receiver in the $1.55 \mu \mathrm{m}$ waveband). The network can be upgraded by alocal ATM switch (dashed lines).

multipoint) must be supported, besides which, the total network capacity is expected to increase significantly. Since it is at present almost impossible to foresee which applications will become prevalent, advanced BCPN's must have great flexibility and must be able to supply a high transport capacity.

Coming back to Fig. 1 showing the multiplex hierarchy, the demonstrators described so far are transporting their services on a corresponding single optical carrier. A higher granularity is obtained in the PTT BCPN demonstrator by introducing ATM multiplexing on each individual carrier [38]-[40]. Thus, the stations in Fig. 7 are individually linked by circuit switching through tuning of corresponding $\mathrm{CT}_{x}-\mathrm{CR}_{x}$ pairs. Each carrier is transporting data at the STM-1 line rate of 155.52 $\mathrm{Mb} / \mathrm{s}$. The multimedia terminals of the linked stations are now communicating via additional TDM multiplexing, which is chosen here as ATM multiplexing in order to obtain a flexible granularity and to interface the future B-ISDN standard.

The basic idea of this concept is as follows:

1) By multiplexing a bundle of ATM circuits onto an optical carrier the concept "ATM optical path" introduced by Sato et al. [41] is realized as a measure to obtain very high capacity networks based on ATM.

2) Since CMC switching allows for point-to-point as well as for point-to-multipoint connections and ATM multiplexing allows for addressing individual terminals, a high number of circuit configurations can be established without any ATM switch in the network (it has to be noted that an ATM switch is indeed not a part of the demonstrator).

3) By introducing ATM switches (a single centralized switch or many decentralized switches within the stations) the network can easily be upgraded to multipoint-to-multipoint connections without changing the physical topology (the PON) and the optical hardware. In the final test and evaluation phase of the demonstrators these issues will be addressed in more detail.

The hardware configuration of the PTT BCPN trial in Fig. 7 consists of five transmitters and receivers connected to each other by means of a passive optical star. The transmitters and
TABLE I

\begin{tabular}{|c|c|c|c|c|}
\hline Short name of the trial & $\begin{array}{l}\text { RENO } \\
\text { demonstrator }\end{array}$ & $\begin{array}{l}\mathrm{BBC} \\
\text { demonstrator }\end{array}$ & $\begin{array}{l}\text { CET } \\
\text { demonstrator }\end{array}$ & $\begin{array}{l}\text { PTT } \\
\text { demonstrator }\end{array}$ \\
\hline Location of the trials & \begin{tabular}{|l|} 
Philips Research \\
Eindhoven, NL
\end{tabular} & $\begin{array}{l}\text { Kingswood } \\
\text { Warren, UK }\end{array}$ & Aveiro, $\mathrm{P}$ & $\begin{array}{l}\text { KPN Research } \\
\text { Leidschendam, } \\
\text { NL } \\
\end{array}$ \\
\hline Application shown & $\begin{array}{l}\text { Cross-connected } \\
\text { core network }\end{array}$ & HDTV in a studio & Videoconference & $\begin{array}{l}\text { multimedia, } \\
\text { medical }\end{array}$ \\
\hline $\begin{array}{l}\text { Number of nodes in } \\
\text { the trial }\end{array}$ & \begin{tabular}{|l|}
3 ocCs \\
(potential: \\
unlimited)
\end{tabular} & 1 passive star & 1 passive star & 1 passive star \\
\hline $\begin{array}{l}\text { Number of terminals } \\
\text { connected to the } \\
\text { nodes in the trial }\end{array}$ & $\begin{array}{l}\text { ( } 3 \text { for testing } \\
\text { only) }\end{array}$ & 5 & 3 & 4 \\
\hline $\begin{array}{l}\text { Number of optical } \\
\text { carriers and line } \\
\text { transmitters realized } \\
\text { Demonstrator concept } \\
\text { allows for }\end{array}$ & $\begin{array}{l}4 \text { in total } \\
16 \text { per link }\end{array}$ & $\begin{array}{l}3 \text { per node } \\
3 \text { per WDM } \\
\text { window }\end{array}$ & $\begin{array}{l}3 \text { per node } \\
128 \text { per node }\end{array}$ & $\begin{array}{l}4 \text { per node } \\
128 \text { per node }\end{array}$ \\
\hline $\begin{array}{l}\text { Number of line } \\
\text { receivers realized }\end{array}$ & 4 in total & 3 & 3 & 4 \\
\hline $\begin{array}{l}\text { Number of potential } \\
\text { line receivers due to } \\
\text { power budget limit } \\
\text { pwithout amplifiers) } \\
\text { (with }\end{array}$ & 16 per link & more than 100 & more than 4000 & more than 4000 \\
\hline $\begin{array}{l}\text { Fibre length in the } \\
\text { trials }\end{array}$ & $\begin{array}{l}60 \mathrm{~km} \text { between } \\
00 \mathrm{cs}\end{array}$ & below $1 \mathrm{~km}$ & average $3 \mathrm{~km}$ & up to $50 \mathrm{~km}$ \\
\hline $\mathrm{OAM}$ and signalling via & $\begin{array}{l}\text { separate fibre } \\
\text { network }\end{array}$ & $\begin{array}{l}\text { Separate } \\
\text { electrical network }\end{array}$ & public ISDN & $\begin{array}{l}\text { WDM overlay at } \\
\lambda=1.3 \mu \mathrm{m}\end{array}$ \\
\hline $\begin{array}{l}\text { Optical center } \\
\text { frequency in } \mathrm{GHz}\end{array}$ & 193036.5 & \begin{tabular}{|l|l|}
193040.8 \\
\end{tabular} & 192150.0 & 192150.0 \\
\hline Carrier spacing in $\mathrm{GHz}$ & 15. & 30 & 20 & 25 \\
\hline $\begin{array}{l}\text { Frequency stabilization } \\
\text { implemented }\end{array}$ & yes & $y \in s$ & yes & no \\
\hline $\begin{array}{l}\text { Bitrate per carrier in } \\
\text { Mbits s }\end{array}$ & 2488.32 & 2488.32 & 140 & 155.52 \\
\hline $\begin{array}{l}\text { Service per carrier } \\
\text { shown }\end{array}$ & $\begin{array}{l}\text { routting of STM- } \\
16\end{array}$ & \begin{tabular}{|l|} 
one \\
uncompressed \\
HDTV in STM-16
\end{tabular} & $\begin{array}{l}\text { one PAL video } \\
\text { channel }\end{array}$ & ATM streams \\
\hline Modulation scheme & CPFSK & CPFSK & FSK & FSK \\
\hline Coding scheme & NRZ & NRZ & \begin{tabular}{|l} 
Manchester \\
\end{tabular} & Manchester \\
\hline Level of demonstration & field trial & application pilot & application pilot & application pilot \\
\hline
\end{tabular}

receivers are distributed among four stations. Each station comprises at least one audio/video (de)coder and an ATM (de)multiplexer.

The use of a passive optical network implies that all information is sent to all subscribers. Therefore, in many applications, network security is important. Implementation of network security functions is introduced in the demonstrator at three levels: User authentication during call setup, exchange of encryption keys, and high-speed encryption of user data. Since encryption is performed on the ATM adaption layer, services at various bit-rates, multiplexed on a single CMC channel, can be encrypted separately. Dedicated hardware and software is part of the demonstrator in order to make encryption of the ATM data stream possible.

Network control is another important aspect in the BCPN concept. Network control includes three main aspects: Callcontrol, wavelength management, and security/key control. In the BCPN a direct detection overlay network on the same fiber infrastructure at $\lambda=1.3 \mu \mathrm{m}$ is used for the network control functions [42].

A third important aspect tested in the demonstrator is optical amplification. The optical amplifier (EDFA) will either compensate the splitting loss in the passive optical star or the loss in the length of installed fiber. In the demonstrator two configurations are tested successfully: Unidirectional traffic with a transmissive star and an unidirectional optical amplifier, and bidirectional traffic with a reflective star and a bidirectional optical amplifier [43], [44].

\section{E. COBRA Demonstrators Overview}

The table on the following page summarizes main parameters of our demonstrators. Also, some technical details which 


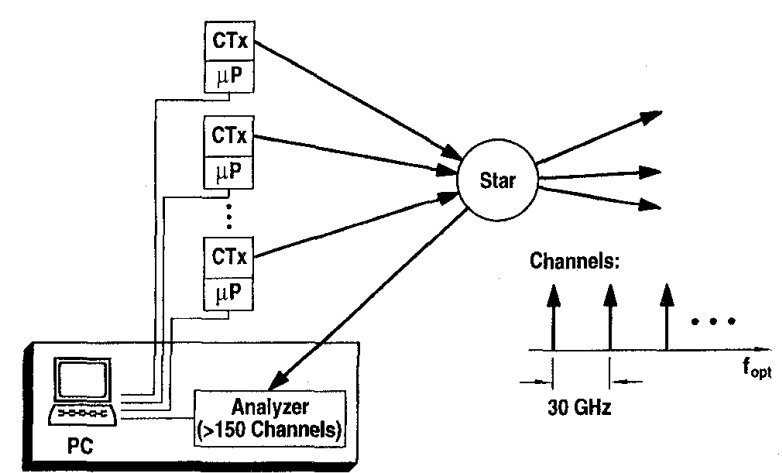

Fig. 8. The Wavelength Manager for controlling coherent transmitters.

are not explicitly mentioned in the foregoing chapters are listed here.

\section{SUBSYSTEMS AND COMPONENTS}

This chapter summarizes some CMC related hardware developments within the COBRA project.

1) The Wavelength Manager: In WDM and CMC networks a wavelength manager in general is responsible for three functions:

1) Monitoring the status of all WDM/CMC channels

2) Stabilization of the transmitter frequencies

3) Switch-off a transmitter which fails.

Since the temperature stabilized transmitter lasers are operating within their predefined windows and with very low intrinsic frequency drift, all demonstrators have been working during the demonstration periods without the explicit necessity of additional control. However, for large networks with a large number of carriers, and in order to maintain a high reliability, wavelength control is indispensible. The wavelength manager developed in the COBRA project is described in detail in [45]. It consists of a commercial high resolution scanning Fabry-Perot spectrum analyzer featured with a galvatron reference (Kr-line at $1547.825 \mathrm{~nm}$ ). The total absolute accuracy of transmitter frequency control is within $2.5 \mathrm{GHz}$, the relative accuracy is below $200 \mathrm{MHz}$.

The wavelength manager was implemented in the demonstrator at BBC controlling the transmitters as shown schematically in Fig. 8.

2) Laser With $1600 \mathrm{GHz}$ Tuning Range: BH-TTG lasers, fabricated by an all-MOVPE process, have been developed with an active region comprising six strained quaternary quantum-wells. An optimized $n$-contact geometry (doublesided arrangement) is used. By applying either forward or reserve bias to the tuning region, the continuous tuning range has been extended to the record value of $13.2 \mathrm{~nm}(1.6 \mathrm{THz})$. An output power level above $1 \mathrm{~mW}$ can be maintained over 12 $\mathrm{nm}$ tuning range, with the linewidth remaining below $30-40$ $\mathrm{MHz}$ [10]. Work has been carried out on TTG-structures with current blocking layers for improved current confinement and therefore enhanced output power.

3) Lasers With Flat FM-Response From 0 to Above 3 GHz: A new type of laser has been developed that solves the problem of the low-frequency dip in the FM-response of conventional lasers. This QCSE (quantum confined Stark effect) TTG (tunable twin guide) laser shows an extremely flat FM-response from dc to 3 to $4 \mathrm{GHz}$ and allows simultaneously wavelength tuning [46]. Two versions-with polyimid layer for lowest capacitance and without polyimid but very small contact pads - have been produced.

4) Common Laser Designs for Transmitter and Local Oscillator: The QCSE-TTG laser has been found to be suitable for both the transmitter and the receiver local oscillator. For all types of single and double-section DFB lasers investigated, it appeared very difficult to meet the linewidth specification in combination with the low and high cut-off frequency specifications for the FM-response. A three-section tunable DBR laser has however been found to be successful, and also able to function as both transmitter and local oscillator [47]. For the transmitter, the FM-response of the modulated Bragg section was flattened to $2.5 \mathrm{GHz}$ by means of an external electronic equalization circuit.

5) Integrated InP-Based Polarization Controller: An integrated InP-based polarization controller having the "semiinsulating embedded ridge stucture" has been developed [48], [49]. The structure is fabricated in three epitaxy steps and by a combination of wet and dry chemical etching. A special procedure was developed, resulting in a completely flat regrown structure. Electrical measurements on the regrown structure showed leakage currents to be negligible.

6) Micro-Optical Polarization Hybrid: A novel fully packaged micro-optical polarization diversity hybrid, showing high performance and being extremely fabrication and alignment tolerant was designed. The design employs highly parallel glass plates, which result in parallel and equidistant input and output beams, thereby eliminating critical fabrication and alignment procedures. At the target wavelength of $1550 \mathrm{~nm}$, typical fiber-to-fiber insertion loss is $0.7 \mathrm{~dB}$, balancing is $50 \pm 3$, polarization extinction ratios are better than $>25$ $\mathrm{dB}$, and measured back reflection is smaller than $<-58 \mathrm{~dB}$. Wavelength insensitive behavior has been observed, resulting in a wide useable spectral operating range in excess of 90 nm. The packaged hybrid is robust, reliable, and allows for low-cost fabrication techniques [22]-[24].

7) Low-IF Receiver Design Implemented: A CPFSK receiver has been developed for $2.5 \mathrm{~Gb} / \mathrm{s} \mathrm{NRZ}$ with an IF of 2 $\mathrm{GHz}$ and an IF bandwidth of $4 \mathrm{GHz}$ [18], [50]. This receiver uses a new concept, based on the suppression of the "doubleIF" signal which is generated in the frequency demodulation process. The concept is especially attracive when combined with electrical dispersion compensation techniques.

8) Multichannel EDFA Developed for Bidirectional CMC Operation: An erbium-doped bidirectional fiber amplifier has been developed and tested [51]. It was found that the saturation of the amplifier is homogeneous, i.e., only dependent on the sum of the two bidirectional input powers. Besides, the crosstalk from reflections and backscattering, and the influence of gain saturation and noise processes was being examined. From this analysis, it came out that large reflections, even when causing laser action at $1531 \mathrm{~nm}$, only slightly influenced the coherent bidirectional transmission at $1560 \mathrm{~nm}$. It was also found that the crosstalk from Rayleigh backscattering between 


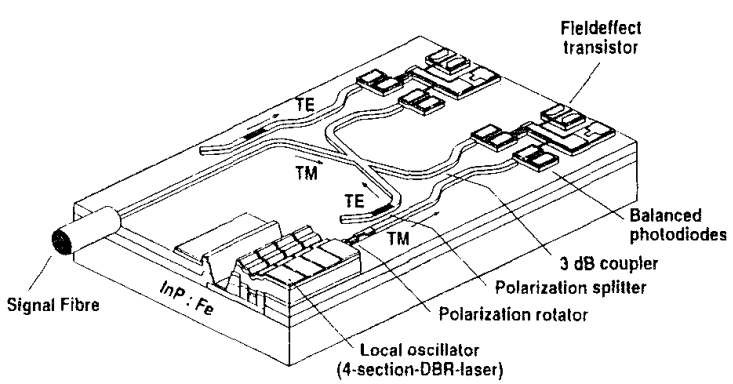

Fig. 9. Schematic view of a fully integrated polarization diversity heterodyne receiver.

counterpropagating signals was increased when the gain was larger than the transmission loss after the EDFA. By a combination of experiment and simulation, it is predicted that up to $10000155 \mathrm{Mb} / \mathrm{s}$ channels can be amplified simultaneously, which corresponds to a total transmission capacity of over 1 $\mathrm{Tb} / \mathrm{s}$. Simulations show that in this case the access shot noise from the amplified channels has a significant influence in the system performance.

9) Fully Integrated Heterodyne Receiver OEIC: Within the COBRA project an OEIC concept has been developed that integrates the basic elements of an isolator-free heterodyne receiver: a four section DBR local laser, a $3 \mathrm{~dB}$ coupler, balanced photodiodes, and a JFET. In the meantime, the HHI has upgraded this device to a fully packaged polarization diversity receiver and has carried out first system experiments. Since this is a breakthrough in component technology with the potential of mass production supporting the introduction of coherent multicarrier technology in the future, a brief outline of this device is given here. On a single 2-inch InP-wafer a number of 100 heterodyne receiver chips of size $9 \times 0.6 \mathrm{~mm}$ shown schematically in Fig. 9 can be produced. The process based on selective area MOVPE involves 23 lithographic and seven epitaxial growth steps for the integration of 17 different photonic elements [25]. A first packaged device was tested at $140 \mathrm{Mb} / \mathrm{s}$ exhibiting a sensitivity of $-34 \mathrm{dBm}\left(\mathrm{BER}=10^{-9}\right)$ and a polarization dependence below $0.5 \mathrm{~dB}$ [52].

\section{CONCLUSION}

The implementation and the test of the four COBRA trials has been finished by end of 1995 . The consortium has promoted coherent multicarrier technology and has gained expertise ranging from components technology to practical applications on a service level. The trials are covering different network segments for the evaluation of specific practical aspects. The RENO demonstrator shows that the flexibility of today's SDH-based core networks can be increased by CMC technology. The demonstrator in the BBC TV studio has proven the high capacity of an internal passive optical network and the simplicity to access ultra-broadband sources. The videoconference trial at CET demonstrates a fastidious service with real users in an operational environment and the trial at KPN Research a high capacity business customer network supporting ATM based multimedia communication.

\section{ACKNOWLEDGMENT}

This paper is written by the members of the Working Group Systems of the COBRA project. However, we wish to acknowledge the work of all our colleagues within the consortium. We also acknowledge the support of our individual companies and the support by the Commission of the EU within the RACE phase II program. We thank B. Mikulski for performing the manuscript and G. Reise for the drawing the figures.

\section{REFERENCES}

[1] E. J. Bachus, I. Borges, P. Demeester, A. Ebberg, G. Heydt, G. D. Khoe, A. C. Labrujere, B. Mikulski, and J. R. Rawsthorne, "COBRA-Flexible broadband networks," First R2065 COBRA Report, Sept. 1992.

[2] E. J. Bachus, C. R. Batchellor, I. Borges, P. Demeester, G. Depovere, A. Ebberg, M. B. Ferreira, G. D. Khoe, A. C. Labrujere, B. Mikulski, J. R. Rawsthorne, G. Reise, and N. Wauters, "COBRA-Flexible broadband networks," Second R2065 COBRA Report, Aug. 1993.

[3] E. J. Bachus, I. Borges, P. Demeester, G. Depovere, A. Ebberg, G. D. Khoe, O. J. Koning, and J. R. Rawsthorne, "COBRA-Flexible broadband networks," Third R2065 COBRA Report, Sept. 1994.

[4] E. J. Bachus, T. Almeida, P. Demeester, G. Depovere, A. Ebberg, M. Ferreira, G. D. Khoe, O. J. Koning, J. R. Rawsthorne, and N. Wauters, "COBRA-Flexible broadband networks," Fourth R2065 COBRA Report, Sept. 1995

[5] S. Kawanishi, H. Takara, T. Morioka, O. Kamatani, K. Takiguchi, T. Kitoh, and M. Saruwatari, "400 Gbit/s TDM transmission of $0.98 \mathrm{ps}$ pulses over $40 \mathrm{~km}$ employing dispersion slope compensation," OFC '96, San José, CA, vol. PD24, Feb. 26-Mar. 1, 1996.

[6] H. Onaka, H. Miyata, G. Ishikawa, K. Otsuka, H. Ooi, Y. Kai, S. Kinoshita, M. Seino, H. Nishimoto, and T. Chikama, "1.1 Tb/s WDM transmission over a $150 \mathrm{~km} 1.3 \mu \mathrm{m}$ zero-dispersion single-mode fiber," OFC 96, San José, CA, vol. PD19, Feb. 26-Mar. 1, 1996.

[7] T. Morioka, H. Takara, S. Kawanishi, O. Kamatani, K. Takiguchi, K. Uchiyama, M. Saruwatari, H. Takahashi, M. Yamada, T. Kanamori, and H. Ono, "100 Gbit/s $\times 10$ channel OTDM/WDM transmission using a single supercontinuum WDM source," OFC'96, San José, CA, vol. PD21, Feb. 26-Mar. 1, 1996.

[8] E. J. Bachus, "Transparency in optical networks," EFOC\&N '93, The Hague, Proc. Papers on networks, pp. 219-224, June 30-July 2, 1993.

[9] G. D. Khoe, G. Heydt, I. Morgan, P. Demeester, A. Ebberg, A. Labrujere, and J. Rawthorne, "Coherent multicarrier technology for implementation in the customer access," J. Lightwave Technol., vol. 11, pp. 695-713, May 1993.

[10] T. Wolf, S. Illek, J. Rieger, B. Borchert, and M.-C. Amann, "Tunable twin-guide (TTG) distributed feedback laser with over $10 \mathrm{~nm}$ continuous range," Electron. Lett., vol. 29, pp. 2142-2125, 1993.

[11] M. Bagley, R. Wyatt, D. J. Elton, H. J. Wickes, P. C. Spurdens, C. P. Seltzer, D. M. Cooper, and W. J. Devlin, "242 nm continuous tuning from a grin-SC-MQW-BH InGaAsP laser in an extended cavity," Electron. Lett., vol. 26, no. 4, pp. 267-269, 1990.

[12] P. W. Hooijmans and M. T. Tomesen, "Analytical analysis of IFpenalties for different FSK and CPFSK detection schemes," J. Lightwave Technol, vol. 10, pp. 649-659, May 1992.

[13] P. W. Hooijmans, M. T. Tomesen, G. F. G. Depovere, R. A. J. M. van Gils, F. A. J. Dumont, and P. H. G. M. Thijssen, "1 Gbit/s CPFSK phase diversity optical transmission for high band width efficiency," in Proc. 18th ECOC, Berlin, Sept. 27-Oct. 1, 1992, paper We-A8.3.

[14] C. R. Batchellor, M. G. Holliday, and A. M. Thorley, "A novel coherent communications transceiver," in Proc. 19th ECOC, Montreux, Sept. 12-16, 1993, paper WeP9.4.

[15] P. Hooijmans, M. Tomesen, G. Depovere, R. van Gils, F. Dumont, and P. Thijssen, "I Gbit/s CPFSK phase diversity optical transmission for high bandwidth efficiency," in Proc. I8th ECOC, Berlin, Sept. 27-Oct. 1, 1992, paper WeA8.3, pp. 357-360.

[16] M. Tomesen, P. Hooijmans, C. Wong, G. Depovere, L. Tiemeijer, H. van Tongeren, and J. Kokkelink, "Novel single laser coherent transceiver with a semiconductor optical amplifier as signal booster," in Proc. 18th ECOC, Berlin, Sept. 27-Oct. 1, 1992, paper WeA8.6, pp. 369-372.

[17] P. W. Hooijmans and M. T. Tomesen, "Analytical analysis of IFPenalties for different FSK and CPFSK detection schemes," J. Lightwave Technol., vol. 10. no. 5, pp. 649-659, 1992. 
[18] M. Tomesen, G. Depovere, R. van Gils, R. Witlox, D. Schouten, E. Pennings, and A. Staring, "Novel heterodyne CPFSK receiver allowing dispersion equalization in a narrow IF bandwidth starting from nearly DC," in Proc. 20th ECOC, Firenze, Sept. 25-29, 1994, vol. 1, pp. 73-76.

[19] E. Meissner, H. Rodler, and M. Lades, "Pattern independent $2.5 \mathrm{Gbit} / \mathrm{s}$ AMI-CPFSK transmission with $-44 \mathrm{dBm}$ receiver sensitivity," Electron. Lett., vol. 30, no. 4, pp. 345-346, 1994.

[20] E. Meissner, M. Lades, and R. Rodler, "Optical 2.5 Gbit/s heterodyne receiver with an IF of only $3.0 \mathrm{Ghz}$ and a reveiver sensitivity of 46.6 dBm," in Proc. 20th ECOC, Firenze, Sept. 25-29, 1994, vol. 2, pp. $781-784$.

[21] R. Noé, H. J. Rodler, A. Ebberg, G. Gaukel, B. Noll, J. Wittmann, and F. Auracher, "Comparison of polarization handling methods in coherent optical systems," J. Lightwave Technol., vol. 9, no. 10, pp. 1353-1366, 1991.

[22] E. C. M. Pennings, D. Schouten, and G. D. Khoe, "Ultra fabrication tolerant micro-optical polarization-diversity hybrid," in Proc. 20 th ECOC, Firenze, Sept. 25-29, 1994, vol. 1, pp. 217-220.

[23] E. C. M. Pennings, D. Schouten, R. A. J. C. M. van Gils, G. F. G Depovere, and G. D. Khoe, "Fully-packaged ultra fabrication-tolerant micro-optical polarization-diversity hybrid," in Proc. of $\mathrm{OFC}^{\prime} 95$, San Diego, CA, Feb. 26-Mar. 3, 1995

[24] E. C. M. Pennings, D. Schouten, G. D. Khoe, R. A. J. C. M. van Gils, and G. F. G. Depovere, "Ultra fabrication tolerant fully packaged micro-optical polarization diversity hybrid," submitted at JLT.

[25] R. Kaiser, D. Trommer, F. Fidorra, H. Heidrich, S. Malchow, D. Franke, W. Passenberg, W. Rehbein, H. Schroeter-Janßen, R. Stenzel, and G. Unterbörsch, "Monolithically integrated polarization diversity heterodyne receivers on GaInAsP/InP," Electron. Lett., vol. 30, pp. 1446-1447, 1994.

[26] ITU-T Recommendation G.803, "Architectures of transport networks based on the synchronous digital hierarchie (SDH)," Mar. 1993.

[27] N. Wauters, P. Demeester, and G. F. G. Depovere, "GTNA representation of optical cross-connected networks," in Proc. EFOC\&N '95 Conf. European Fiber Optic Commun. Networks, Brighton, England, June 27-30, 1995

[28] _ , "Functional representation of optical transport networks and surveillance monitoring techniques," in I0th Int. Conf. Integrat. Optics Optical Fiber Commun., IOOC '95, Hong Kong, June 26-30, 1995.

[29] G. Depovere, M. Tomesen, P. Hooijmans, N. Wauters, and P. Demeester, "A flexible cross-connect network using multiple optical carriers," in Proc. 19th ECOC, Montreux, paper TuP4.5, Sept. 12-16, 1993.

[30] G. Depovere, M. Tomesen, R. v. Gils, N. Wauters, D. Vercauteren, and P. Demeester, "Laboratory demonstration of a $2.5 \mathrm{Gbit} / \mathrm{s}$ SDH-compatible optical cross-connect network," in Proc. 20th ECOC, Firenze, Sept. 25-29, 1994, vol. 2, pp. 571-574.

[31] N. Wauters, C. Vercauteren, P. Demeester, P. Lagasse, G. Depovere, and P. Hooijmans, "Introduction in SDH-networks of reconfigurable nodes using optical frequency division multiplexing," in Proc. 19th ECOC, Montreux, Sept. 12-16, 1993.

[32] G. D. Khoe, Tutorial, "Coherent techniques for flexible capacity traffic and access," in Proc. OFC/IOOC'93, San Jose, CA, Tutorial Digest, paper ThE, Feb. 21-26, 1993, pp. 177-225.

[33] N. Wauters and P. Demeester, "Wavelength requirement and survivability in WDM cross-connected networks," in Proc. 20th ECOC, Firenze, vol. 2, Sept. 25-29, pp. 589-592, 1994.

[34] N. Wauters and P. Demeester, "Influence of wavelength translation in optical frequency multiplexed networks," in IEEE/LEOS 1994, Summer Topic. Meet. Optic. Networks Enabling Technol., Lake Tahoe, NV, July 11-13, paper M4.3, 1994.

[35] G. D. Khoe, "Coherent multicarrier lightwave technology for flexible capacity networks," IEEE Commun. Mag., pp. 40-51, Mar. 1994.

[36] C. R. Batchellor, B. T. Debney, A. M. Thorley, G. D. Khoe, C. v. Helmolt, F. Auracher, and P. Lagasse, "System assessment of the RACE 1010 multi-channel demonstrator," Optic. Quantum Electron., Special Issue on Advances in Optoelectronics in Europe, vol. 26, pp. S517-S528, 1994

[37] C. R. Batchellor, B. T. Debney, A. M. Thorley, T. J. B. Swanenburg, G. Heydt, F. Auracher, and P. Lagasse, "A coherent multichannel demonstrator," IEE Colloq. RACE Optic. Syst. Demonstrators, London, Digest no. 1993/115, May 17, 1993.

[38] O. J. Koning, R. J. Brinkman, M. O. van Deventer, P. H. A. Venemans, L. Wennekes, J. P. Boly, M. K. de Lange, J. Vanderwege, B. Meuris, and A. Ebberg, "A multi-carrier business customer premises network," in Proc. The European Symp. Advan. Networks Services, Amsterdam, Mar. 20-23, 1995.

[39] A. C. Labrujere, M. O. van Deventer, and O. J. Koning, "Coherent multi-channel technology in the local loop," Fiber Optic Networks
Video-Commun. Conf. '93, Berlin, Apr. 1993.

[40] O. J. Koning, A. C. Labrujere, P. H. A. Venemans, J. P. Boly, R. J. Brinkman, and M. K. de Lange, "A flexible broadband coherent optical system for application in a business customer premises network," RACE Open Workshop Broadband Access, Nijmegen, The Netherlands, June 1993.

[41] K. Sato, S. Okamoto, and H. Hadama, "Optical path layer technologies to enhance B-ISDN performance," in ICC '93, Proc., pp. 1300-1307.

[42] B. Meuris, B. Staelens, J. Zhou, I. Vandewege, O. J. Koning, R. J. Brinkman, and P. H. A. Venemans, "Implementation of a control network and wavelength management system for a coherent multicarrier business customer premises network," in Proc. EFOC\&N ' 95 Conf. European Fiber Optic Commun. Networks, Brighton, England, June 27--30, 1995.

[43] M. O. van Deventer, O. J. Koning, and A. J. Lous, "Interaction between channels in a bidirectionally amplified multicarrier system," in Proc. 20th ECOC, Firenze, Sept. 25-29, 1994, vol. 1, pp. 411-414.

[44] M. O. van Deventer and O. J. Koning, "Crosstalk and channel spacing in a coherent multichannel system using erbium doped fiber amplifiers," IEEE Photon. Technol. Lett., vol. 6, pp. 260-262, 1994.

[45] U. Krüger, K. Krüger, C. R. Batchellor, U. Fischer, C. v. Helmolt, and U. Nagengast, "Wavelength manager covering the EDFA-band and capable of controlling hundreds of transmitters," 20th ECOC, Florence, Italy, vol. TuP 28, Sept. 25-29, 1994.

[46] T. Wolf, K. Droegenmueller, B. Borchert, H. Westermeier, E. Veuhoff, and H. Baumeister, "Tunable twin-guided lasers with flat frequency modulation response by quantura confined stark effect," Appl. Phys. Lett., no. 60, pp. 2472-2474, 1992.

[47] A. A. M. Staring, J. J. M. Binsma, P. I. Kuindersma, E. J. Jansen, P. J. A. Thijs, T. van Dongen, and G. F. G. Depovere, "Wavelengthindependent output power from an injection-tunable DBR laser," IEEE Photon. Technol. Lett., vol. 6, pp. 147-149, Feb. 1994.

[48] P. Kaczmarski, G. M. Morthier, R. Baets, B. H. Verbeek, and E. C. M. Pennings, "Numerical analysis of electrooptic polarization rotation in In-based embedded waveguides," in Proc. ECIO'93, Neuchatel, Apr. 18-22, 1993, pp. 13-6/13-7.

[49] P. Kaczmarski, G. M. Morthier, R. Baets, B. H. Verbeek, and E. C. M Pennings, "Analysis of InP-based guided-wave electrooptically rotatable waveplates for polarization transformers," in Proc. OFC/IOOC' '93, San Jose, CA, Feb. 1993, paper WH7.

[50] R. A. J. C. M. van Gils, M. T. Tomesen, and G. F. G. Depovere, "2.5 GBit/s CPFSK system with low IF-frequency," Electron. Lett., vol. 30 , no. 14, pp. 1153-1154, 1994.

[51] O. J. Koning, "An EDFA, suitable for bidirectional multi-channel signal amplification," RACE PLI Workshop Optic. Ampl. Applicat., Brussels, July 6, 1994.

[52] U. Hilbk, Th. Hermes, P. Meißner, F.-J. Westphal, G. Jacumeit, R Stenzel, and G. Unterbörsch, "Stable operation of a monolithically integrated InP-heterodyne polarization diversity receiver module including a tunable laser in an experimental OFDM system," in Proc. 20th ECOC, Florence, Italy, Sept. 25-29, 1994, vol. 1, pp. 77-81.

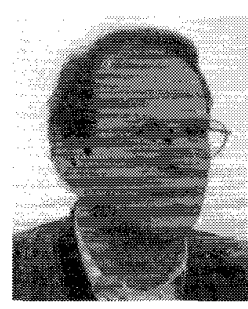

Ernst-Jurgen Bachus was born on Sept. 8, 1941, in Hannover, Germany. He received the Dipl.-Ing. degree and the Dr.-Ing degree in electrical communication from the Technische Universitat, Berlin, in 1972 and 1978 , respectively.

In 1972 he joined the Heinrich-Hertz-Institut, Berlin, working on microwave tchnology, and, since 1978 , in the field of optical communication. He has also worked on fiber optic components, coherent multicarrier techniques, optical measurement techniques and optical networks. He has authored and coauthored more than 35 papers and has served on technical committees of conferences and editorial boards as a member and chairman. He is currently chairman of the Scientific Board of the Heinrich-Hertz-Institut. He has been involved in the EU RACE program and was coordinator of the systems group in the R2065 COBRA project. 


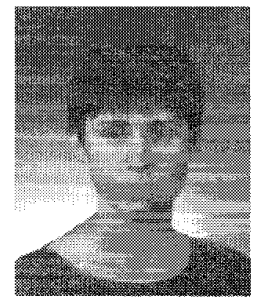

Teresa Almeida was born in Portugal in 1962. She received the physics degree from Oporto University, Portugal, in 1986. From 1987 to 1989 she had a fellowship to work at LIP-Lisbon, in instrumentation for particle physics experiments, related to the Portugese participation on DELPHI experiment at CERN.

She joined CET, the telecommunications research and development center of Portugal Telecom in 1989 as a staff member in the Transmission Systems Division, optical communication area. In 1991 she moved to CET Applied Research Development in the area of optical networks. Her present activites include participation in the R2065 COBRA project, with one application demonstrator running in Aveiro, Portugal.

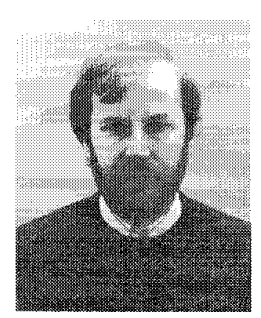

Piet Demeester (M'89) received the M.Sc and $\mathrm{Ph} . \mathrm{D}$. degrees in electrical engineering from the University of Gent in 1984 and 1988, respectively.

Since 1987 he has been employed by the Interuniversity Micro-Electronics Center (IMEC) and works in the department of Information Technology (INTEC) at the University of Gent, where he is a part-time professor. He is coordinating the work on epitaxial growth for HII- $\mathrm{V}$ optoelectronic devices and is responsible for the research on modeling and design of broadband networks.

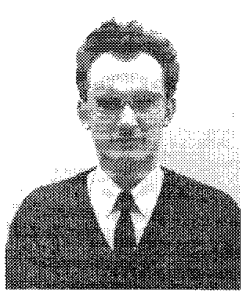

Geert F. G. Depovere was born in Roeselare, Belgium, on March 26, 1965. He received the M.Sc. and Ph.D. degrees in electrical engineering from the University of Gent, Belgium, in 1988 and 1992, respectively. His dissertation describes optical fiber measurement systems and includes experimental as well as theoretical work on coherent and subcarrier multiplexed optical communication systems.

He joined Phillips Research Laboratories, Eind hoven, The Netherlands, in 1992. Since then he has been working in the field of high bitrate coherent multichannel systems and broadband optical network architectures in the group Wideband Communication Systems. His activities included the coordination of the RENO demonstrator within the RACE COBRA R2065 project.

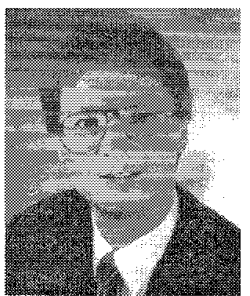

Alfred Ebberg was born in Hemer, Germany, in 1955. He received the M.Sc. and $\mathrm{Ph} . \mathrm{D}$. degrees, both in electrical engineering, from the Ruhr University of Bochum, Germany, in 1982 and 1988, respectively. His dissertation was on fiber optic rotation sensors.

From 1987 to 1995 he worked at Siemens Research Laboratories in Munich. He was engaged in research on broadband optical transmission and switching systems using heterodyne and high speed direct detection techniques, mostly within the framework of the European RACE (R\&D in Advanced Communication Technologies in Europe) program. Since 1995 he has been a Professor for communication techniques at the Fachhochschule Westkueste in Heide, Germany. He has authored and coauthored more than 30 papers and holds several patents. His area of interest has been and continues to be applied research on broadband communication systems.

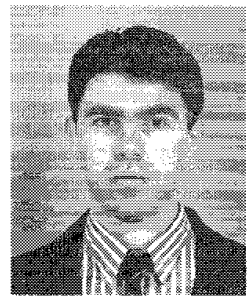

Mario Rui Ferreira was born in Aveiro, Portugal, in 1957. He received his degree in telecommunications engineering from the Aveiro University, Portugal, in 1980.

In 1982 he joined the Project and Development Department in the Aveiro branch of CTT. From 1983 until the present he has been a staff member of CET. His work includes microwave trnsmission and Sound-In-Synchro systems, planning the en largement of several regional telephone networks, design and development of fiber optic transmission systems for the PDH CCITT levels and, from 1988 to 1992, the representation of the Portugese PTT within ETSI TM1 Technical Committee for the optical system and cable aspects. He is currently participating in two RACE projects: COBRA R2065 and FIRST R2014, both with demonstrators installed in Aveiro, Portugal.

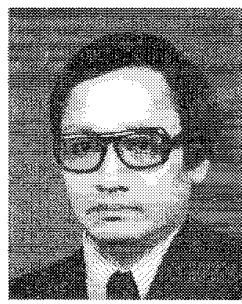

Giok-djan Khoe (S'71-M'71-SM'85-F'91) was born in Mageland, Indonesia, on July 22, 1946 He received the degree in electronic engineering from Eindhoven University of Technology, The Netherlands, in 1971.

He worked at the FOM Institute of Plasma Physics, The Netherlands, on laser diagnostics of plasmas from 1971 to 1972 . In 1973 he joined Philips Research Laboratories, and, in addition, he was appointed as a part- time Professor at Eindhoven University, where he has been a fulltime Professor since 1994. His work has been devoted to single model fiber systems and components. He has more than 40 U.S. patents, has authored and coauthored more than 60 papers, invited papers, and books, and has served on technical committees of conferences and editorial boards of joumals as a member, associate, or chairman. He is closely involved in European Community reserach programs and Dutch national research programs as participant, evaluator, auditor, and program committee member.

Dr. Khoe was the European respresentative at the IEEE/LEOS Board of Governors in 1993-1995. He is now vice president of membership and region 8 activities for that board and Member of the Executive Committee of the IEEE Benelux Section. He has been an IEEE Fellow since 1991.

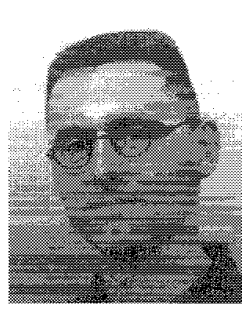

Haag,
Oscar J. Koning was born in Amsterdam, The Netherlands, in 1962. He received the M.Sc degree in physics from the University of Amsterdam in 1988 .

In the same year he joined the KPN Research as a staff member, where he worked on coherent communication systems, optical amplifiers, and advanced optical networks. He has been involved in the ESPIRIT-2054 UCOL (Ultra-Wideband Coherent Optical LAN) and RACE 2065 COBRA research programs. He is now at PTT Telecom b.v. in Den

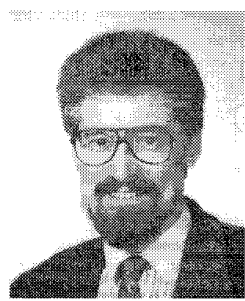

Richard Marsden was born in Wellingborough, England, in 1948. He received the B.A. in physics from the University of Oxford in 1969

After graduating, he joined the Research Department of the British Broadcasting Corporation, working initially on the improvement of televi sion pictures derived from film. Since 1988 he has worked on a number of RACE projects, mainly concerned with optical fiber transmission and routing and network interfacing for TV signals.

Mr. Marsden is a member of the IEEE and a fellow of the British Kinematograph, Sound and Television Society. 


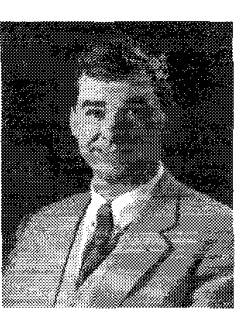

John Rawsthorne was born in West Bromwich, U.K., in 1956. He received the B.Eng. degree in electrical and electronic engineering at Bradford University in 1985.

In 1991 he joined GMMT at Caswell to work within the optoelectronics devices department, coming from Thomson Consumer Electronics (TCE), where he was a Senior Development Engineer in their R\&D laboratory. While working within the European EUREKA program for high definition television, he represented TCE on the committee for HDTV monitor design, setting European standards for HDTV. Since 1991, he has played a prominent role in the RACE II programs R2073 OMAN and R2065 COBRA, having taken over the role as Project Manager of OMAN during 1993. Within this role he has actively participated in the RACE Concertation process, and was elected chairman of RACE Project Line 1, Special Interest Group on Components and Subsystems. He is currently Senior Principal Scientist within the Optoelectronic Devices Department at GEC-Marconi Materials Technology, Caswell.

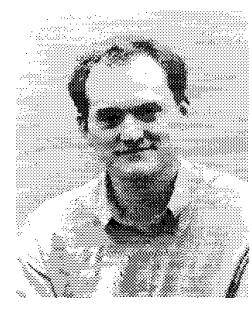

network architectures.
Nic, Wauters was born in Mortsel, Belgium, in 1967. He received the M.Sc. degree in electrical engineering at the University of Gent, The Netherlands, and the postgraduate degree in telecommunications and telematics at the University of Antwerp in 1991 and 1995, respectively.

In 1992 he joined IMEC-University of Gent in the Department of Information Technology (INTEC), where he is active in optical networking. His current research interests include modeling, performance evaluation and dimensioning of optical transport 